\title{
Support for the higher-order factor structure of the WHODAS 2.0 self-report version in a Dutch outpatient psychiatric setting
}

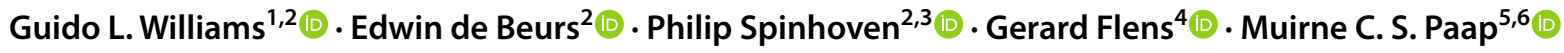

Accepted: 12 May 2021 / Published online: 12 June 2021

(c) The Author(s) 2021

\begin{abstract}
Purpose Previous studies of the World Health Organization Disability Assessment Schedule 2.0 (WHODAS 2.0) interview version suggested a second-order model, with a general disability factor and six factors on a lower level. The goal of this study is to investigate if we can find support for a similar higher-order factor structure of the 36-item self-report version of the WHODAS 2.0 in a Dutch psychiatric outpatient sample. We aim to give special attention to the differences between the non-working group sample and the working group sample. Additionally, we intend to provide preliminary norms for clinical interpretation of the WHODAS 2.0 scores in psychiatric settings.

Methods Patients seeking specialized ambulatory treatment, primarily for depressive or anxiety symptoms, completed the WHODAS 2.0 as part of the initial interview. The total sample consisted of 770 patients with a mean age of 37.5 years $(S D=13.3)$ of whom 280 were males and 490 were females. Several factorial compositions (i.e., one unidimensional model and two second-order models) were modeled using confirmatory factor analysis (CFA). Descriptive statistics, model-fit statistics, reliability of the (sub)scales, and preliminary norms for interpreting test scores are reported.

Results For the non-working group, the second-order model with a general disability factor and six factors on a lower level, provided an adequate fit. Whereas, for the working group, the second-order model with a general disability factor and seven factors on a lower level seemed more appropriate. The WHODAS 2.0 36-item self-report form showed adequate levels of reliability. Percentile ranks and normalized T-scores are provided to aid clinical evaluations.

Conclusion Our results lend support for a factorial structure of the WHODAS 2.036 -item self-report version that is comparable to the interview version. While we conjecture that a seven-factor solution might give a better reflection of item content and item variance, further research is needed to assess the clinical relevance of such a model. At this point, we recommend using the second-order structure with six factors that matches past findings of the interview form.
\end{abstract}

Keywords WHODAS 2.0 $\cdot$ Functioning $\cdot$ Measurement $\cdot$ Dimensionality $\cdot$ Norm scores $\cdot$ Mental healthcare

Guido L. Williams

g.williams@thubble.nl

1 Dimence Foundation, Specialized Assessment and Treatment Division, Department of Digital Mental Healthcare, Dimence Group, Deventer, The Netherlands

2 Institute of Psychology, Leiden University, Leiden, The Netherlands

3 Department of Psychiatry, Leiden University Medical Center, Leiden, The Netherlands

4 Alliance for Quality in Dutch Mental Health Care, Akwa GGZ, Utrecht, The Netherlands

5 Nieuwenhuis Institute for Educational Research, Faculty of Behavioural and Social Sciences, University of Groningen, Groningen, The Netherlands

6 Clinic Mental Health and Addiction, Oslo University Hospital, Oslo, Norway
Adequate levels of functioning play a key role in successful aging in regard to deriving meaning and purpose in life, and have various favorable effects on mental and physical health $[1,2]$ According to the definition of the World Health Organization (WHO), health is "a state of complete physical, mental and social well-being and not merely the absence of disease or infirmity." In line with this definition, it is safe to assume that merely using a medical classification and an inventory of symptoms, yield insufficient information on the level of care that is needed and the expected outcomes of healthcare. Patients do not only seek treatment for symptom relief, but often also want to resolve interpersonal problems and learn to cope with their struggles in daily functioning and (social) participation, caused by their (mental) illness. Furthermore, collecting data on the level of functioning 
could play an important role in the planning, monitoring, evaluation, and outcome of healthcare [3].

The International Classification of Functioning, Disability and Health (ICF), published by the WHO, offers a standardized method for integrating the level of functioning in a diagnosis [4]. The ICF offers (coded) descriptions of the level of functioning in body functions (including mental functions), body structures, daily activities and (social) participation. The World Health Organization Disability Assessment Schedule 2.0 (WHODAS 2.0) [5], which is directly connected to the ICF concepts, is recommended by the WHO and the International Consortium for Health Outcomes Measurement (ICHOM) as a standard measure for the level of functioning [6]. The Diagnostic and Statistical Manual of Mental Disorders, Fifth Edition (DSM-5) by the American Psychiatric Association (APA), also promotes the WHODAS 2.0 as the successor of the Global Assessment of Functioning (GAF), in order to provide a more accurate measure of the global level of disability in psychiatric patients $[7,8]$.

The WHODAS 2.0 was based on a large cross-cultural study, encompassing samples from the general population, populations with physical problems, populations with mental or emotional problems, and populations with problems related to alcohol and drug use [8-10]. The WHODAS 2.0 was found to have good psychometric properties across all included samples. Construct validity of the scales was evaluated by conducting principal components analysis and the item responses were analyzed for ordinality applying the partial credit model. Finally, 34 items of the originally 96 proposed items were eligible for inclusion in the WHODAS 2.0, and two additional items concerning sexual activity and the impact of the disability on the family, were incorporated in the 36-item version. From exploratory factor analysis, the researchers suggested a second-order model, with a general disability factor and six factors on a lower level in different cultures and populations which was replicated by conducting confirmatory factor analysis [9].

For the initial development of the WHODAS 2.0, an interview version was used. However, in clinical practice it might be convenient and efficient to make use of a self-report version. Some authors have suggested that self-evaluations could give a more accurate measure of patient symptoms in psychiatric assessments as they reduce the risk of bias on the part of the clinicians [10]. Furthermore, there are indications that for some symptoms, ratings by patients seem to be more conservative than ratings by proxy; i.e., patients tend to report fewer symptoms than clinicians or family $[3,11]$. Still, studies on the self-report version seem to be scarce. To our knowledge there are no self-report studies of the full 36-item self-report Dutch WHODAS examining the internal structure and/or providing norms for interpreting the scores for the general Dutch population or Dutch psychiatric population. An international systematic review on the use and psychometric properties of the WHODAS 2.0 [10] identified 810 studies from 94 countries published between 1999 and 2015, using the WHODAS (i.e., the 36-item version, 12 -item version or the combined $12+24$ item version in various formats: interview-administered, self-administered, and/or proxy-administered). From this review it is not clear how many studies used the 36-item patient self-report (i.e., self-administered) version specifically; but only fifteen of these studies were conducted in the field of psychiatry in The Netherlands using a 36-item format. However, these Dutch studies did not examine the psychometric properties of the WHODAS, but mostly used the WHODAS as an independent measure of functional impairment. Only two of these studies reported on reliability (Cronbach's Alpha), and one study reported a mean score with a standard deviation for the WHODAS. For these reasons, it should be evaluated whether the factor structure of the WHODAS 2.0 interview version is also adequate for the self-report version.

In addition, some sample characteristics of the initial international field studies [5] raise questions regarding the generalizability of these field studies to the population of psychiatric patients [12]. According to the WHODAS 2.0 manual, $27.6 \%$ and $25.7 \%$ of the total international sample $(N=1431)$, respectively, had mental or emotional problems [5]. The proportion of Dutch participants in the total international sample was relatively small (WHODAS 2.0 field studies: Item reduction and feasibility $n=47$, i.e., approx. $3 \%$ of the total sample; WHODAS 2.0 field studies: Reliability and validity $n=50$, i.e., approx. $3.5 \%$ of the total sample). It is therefore important to address the generalizability of the WHODAS 2.0; in particular, regarding the group of Dutch psychiatric patients that participated in our research. Moreover, the Dutch translation of the DSM-5 was already published in 2014, including the Dutch WHODAS 2.036 -item self-report as a replacement for the GAF [13]. Since 2017, a DSM-5 classification has been mandatory in the Dutch mental health care system in order to be eligible for reimbursement for treatments by health insurance companies. However, due to the lack of Dutch psychometric data, clinicians have chosen to continue using the outdated GAF. Meanwhile, the Dutch Healthcare Institute, responsible for formulating national healthcare quality standards and treatment guidelines, also favors the WHODAS 2.0 as a measure for the level of functioning in psychiatric patients [14].

The main aim of this study is to investigate whether the original factor structure (i.e., a second-order model, with a general disability factor and six factors on a lower level), is supported for the Dutch self-report version. We also focus on the differences between the non-working group sample and the working group sample, because non-working is hypothesized to be associated with higher scores on the WHODAS 
2.0 i.e., higher levels of disability. In addition, we provide preliminary norm data to allow for interpretation of WHODAS 2.0 scores in psychiatric settings.

\section{Method}

\section{Data collection}

The patients in this study were referred by their general practitioner to the Ambulatory Specialized Assessment and Treatment Division of the Dimence foundation from the Dimence Group (DG), a Dutch mental health care facility for psychiatric disorders. After referral, the patients were invited for an initial diagnostic interview by at least one (specialized) healthcare professional. After the initial interview, patients received a primary diagnosis. Before or after this appointment, the patients filled out the WHODAS 2.036 -item self-report form on a computer, as part of the standard assessment during the admission process. For this study, all patients who completed the WHODAS 2.0 within a 50-day window (i.e., before/after the initial interview) were included. The raw, coded, WHODAS 2.0 scores were obtained from the data warehouse of the DG by a senior business intelligence developer of the Business Intelligence Team. Besides the item scores, the following demographic data were also available from the database: gender, diagnosis, age, treatment region, education level and date of completion of the WHODAS 2.0.

\section{Materials}

The WHODAS 2.0 self-report version contains 36 items for assessing problems related to (mental) health conditions experienced during the past 30 days. Ratings were given on a 5-point Likert-scale with higher scores reflecting higher levels of disability: (1) none, (2) mild, (3) moderate, (4) severe, (5) extreme.

The WHODAS 2.0 produces a mean score ${ }^{1}$ for all items and for each of the six subscales of functioning domains: D1 cognition (6 items; e.g., "Concentrating on doing something

\footnotetext{
1 The WHO manual proposes two scoring procedures, one based on classical test theory (CTT) and one based on item response theory (IRT). Since many clinicians may not have the resources, time or knowledge to use the complex IRT scoring method, we opted for the recommended 'simple' CTT based scoring as a method of choice in busy clinical settings. Rather than using a sum score, however, we chose to use a mean score. The main reason for this is that sum scores are less suitable for comparisons between the working and non-working samples in our study, because these groups responded to a different number of items. Importantly, the percentage scores mentioned in the manual of the WHO seem only to apply to the more complex IRT-based scoring.
}

for ten minutes"); D2 mobility (5 items; e.g., "Standing up from sitting down"); D3 self-care (4 items; e.g., "Getting dressed"); D4 getting along (5 items; e.g., "Maintaining a friendship"); D5 life activities (household: 4 items; e.g., "Taking care of your household responsibilities;" and work/ school: 4 items; e.g., "Your day-to-day work/school"); and D6 participation (8 items; e.g., "How much of a problem did you have because of barriers or hindrances in the world around you?").

It should be noted that the life activities domain D5 of the WHODAS 2.0 contains two sub-clusters: household (4 items) and work/school activities (4 items). Respondents who do not participate in work- or school-related activities are instructed to skip the corresponding items. This could lead to relatively lower overall disability scores for the nonworking group, compared to respondents participating in work- or school-related activities who are reporting difficulties in this domain [15]. Therefore, the scores of the working group and the non-working group could not be directly compared, and for that reason we calculated mean scores instead of sum scores.

Over the past few years, a number of international initiatives have advocated the conversion of raw scores into T-scores in an effort to harmonize measurements results and to facilitate the comparability and ease of interpretation across different measurement instruments [6, 16-18]. For that reason, we included a conversion table to convert raw mean scores into T-scores (table S8).

\section{Analysis}

All analyses were performed in R, version 3.6.1 [19]. The following additional packages were used: lavaan version 0.6.5. [20]; tidyverse version 1.2.1. [21]; psych version 1.8.12. [22]; semTools version 0.5.2.916 [23] and semPlot version 1.1.2. [24]; CTT version 2.3.3. [25]; and effsize version 0.7.8. [26].

We described the characteristics of the psychiatric population. In addition, we assessed the dimensionality conducting confirmatory factor analysis (CFA). Due to the missing values for the non-working group in the life activities domain D5, the CFAs were performed separately for the working group (36 items) and non-working group (32 items, with scale D5 being defined as D5.1 + D5.2+D.5.3+D5.4). Additionally, to analyze the effect of the missing values in the non-working group, we conducted a CFA for all models on the total sample with imputation. For this calculation we used the mean scores of the working sample as proposed by the WHODAS 2.0 manual [5].

We compared three models to investigate the factorial structure of the WHODAS 2.0: 
1. A unidimensional model. Here, all items were treated as indicators where all items loaded on one single factor.

2. A second-order factor model using 6 subscales. The association among the subscales was modeled by adding a second-order factor. This factor structure is suggested as the preferred model for the initial interview version of the WHODAS 2.0 by Üstün et al. [9].

3. A second-order factor model using 7 subscales for the working group. For this model we added a factor by splitting subscale 5 (life activities) into two different components (household and work/school activities). This model could only be applied to the working group and the imputed sample.

For the sake of completeness, additional information regarding correlated trait models with six and seven factors respectively is available in Online Supplement A.

We measured reliability by calculating Omega. We chose to favor Omega over Cronbach's Alpha since Omega gives a more accurate estimate of reliability in case of a higher order structure [27-30]. Although Omega and Cronbach's Alpha can yield different (or similar) results, the general criteria for interpretation apply to both. Reliability estimates of 0.80 and higher were considered sufficient, following recommendations of Nunnally and Bernstein [31], and Lance et al. [32].

Since the items were ordinal in nature, we used the weighted least square mean and variance (WLSMV) estimator $[33,34]$. The WLMSV estimator in lavaan, a package in $\mathrm{R}$, which is used for structural equation modelling including CFA, uses diagonally weighted least squares (DWLS) with robust standard errors and a mean- and variance-adjusted test statistic, to estimate the model parameters with the full weight matrix based on polychoric correlations, using the 'ordered' argument [20]. The factor loading of the first indicator of each latent variable was fixed to 1 . The following CFA fit statistics were considered to be indicative of good fit $[35,36]$ : comparative fit index $(\mathrm{CFI})>0.95$, Tucker-Lewis index $(\mathrm{TLI})>0.95$, root mean square error of approximation (RMSEA) $<0.06$, standardized root mean square residual $(\mathrm{SRMR})<0.08$.

\section{Results}

\section{Descriptive statistics}

The total sample consisted of 770 patients from the Specialized Assessment and Treatment Division of the Dimence foundation from the Dimence Group. The total sample had a mean age of 37.5 years $(S D=13.3$, range $17-67)$ and consisted of 280 males and 490 females (with a mean age of $39.59(S D=13.06)$ and $36.31(S D=12.99)$ years, respectively.
The majority of participants (70\%) had a primary diagnosis of a depressive disorder or an anxiety disorder. For 123 participants (16\%), the primary diagnosis was unknown, because the psychological evaluation was not fully completed at the time of our data collection. Most of the participants, $n=483$ (i.e., $63 \%$ ), were employed (paid, non-paid, self-employed) or went to school. All participants resided in the central-eastern regions of The Netherlands. The mean score for the total sample $(N=770)$ was $2.42(S D=0.71$, skewness $=0.45$, kurtosis $=-0.19$, se $=0.03$ ). More detailed demographics and descriptive statistics are presented in Tables 1 and 2.

An independent samples $t$-test was conducted to compare the mean scores for the working group and non-working group. There was a significant difference in the mean scores between these groups; $t(506.83)=10.979, p<0.001$. The effect size for this analysis ( $d=0.86$; 95\% CI [0.71-1.02]) was found to exceed the convention for a large effect $(d=0.80)$ [37]. This indicates that the mean score for the average patient in the non-working group is 0.86 standard deviation above the mean score for the average patient in the working group.

On examining the distribution of the response categories endorsed per item (see Online Supplement B), it was found that over $55 \%$ of the respondents chose scoring category 1 (indicating no disability) for the mobility items D2.2, D2.3 and D2.5. More than 70\% of the respondents also reported no difficulties with the self-care items D3.1 and D3.2. Interestingly, the participation item D6.6 also was highly positively skewed, as more than half of the respondents indicated no drain on their financial resources due to their health condition, and almost $20 \%$ experienced mild financial difficulties. However, still about a third of all patients reported moderate to extreme problems in relation to their financial situation.

\section{Latent variable modelling}

The unidimensional model did not meet the recommended criteria for a good fit. The fit indices for the multidimensional models were acceptable. We interpreted this as support for the contention that a multidimensional model should be preferred, and that the subscales of the WHODAS 2.0 patient self-report have added value when measuring the level of functioning.

For the non-working group, the second-order model with a general disability factor and six factors on a lower level, as found in the interview version of the initial WHODAS 2.0 studies, provided an acceptable fit (Table 3). The correlated six factor model showed comparable fit (see Online Supplement A).

However, in the working group, not all fit statistics met the desired criteria for the second-order model with six 
Table 1 Demographic characteristics total sample $(N=770)$

\begin{tabular}{|c|c|}
\hline Variable & $M(S D)$ range, $n[\%]$ \\
\hline Age (years) & $37.5(13.1)$ range $17-67$ \\
\hline Male & $39.6(13.1)$ range $18-67$ \\
\hline Female & $36.3(13.0)$ range $17-63$ \\
\hline \multicolumn{2}{|l|}{ Sex } \\
\hline Male & $280[36.4 \%]$ \\
\hline Female & $490[63.6 \%]$ \\
\hline \multicolumn{2}{|l|}{ Education level } \\
\hline Low & $39($ Male $=16[2 \%]$, Female $=23[3 \%])$ \\
\hline Middle & $474($ Male $=166[22 \%]$, Female $=308[40 \%])$ \\
\hline High & $218($ Male $=76[10 \%]$, Female $=142[18 \%])$ \\
\hline Unknown & $39($ Male $=22[3 \%]$, Female $=17[2 \%])$ \\
\hline \multicolumn{2}{|l|}{ Working/school } \\
\hline Yes & $N=483[63 \%]($ Male $=183[24 \%]$, Female $=300,[39 \%])$ \\
\hline No & $N=287[37 \%]($ Male $=97[12 \%]$, Female $=190[25 \%])$ \\
\hline \multicolumn{2}{|l|}{ Primary diagnosis } \\
\hline Depressive disorders & $308($ Male $=124$, Female $=184)$ \\
\hline Anxiety disorders & $225($ Male $=67$, Female $=158)$ \\
\hline Unknown & $123($ Male $=49$, Female $=74)$ \\
\hline Personality disorders & $70($ Male $=18$, Female $=52)$ \\
\hline Neurodevelopmental disorders & $14($ Male $=9$, Female $=5)$ \\
\hline Somatic symptom and related disorders & $13($ Male $=5$, Female $=8)$ \\
\hline Substance-related and addictive disorders & $8($ Male $=5$, Female $=3)$ \\
\hline Schizophrenia spectrum and other psychotic disorders & $4($ Male $=1$, Female $=3)$ \\
\hline Feeding and eating disorders & $2($ Male $=0$, Female $=2)$ \\
\hline Disruptive, impulse control, and conduct disorders & $2($ Male $=2$, Female $=0)$ \\
\hline Dissociative disorders & $1($ Male $=0$, Female $=1)$ \\
\hline
\end{tabular}

Table 2 Descriptive statistics mean scores WHODAS 2.0 for working, non-working and total sample

\begin{tabular}{|c|c|c|c|c|c|c|c|c|c|c|c|c|c|c|c|}
\hline \multirow[t]{2}{*}{ Domain } & \multicolumn{5}{|c|}{ Working $(n=483)$} & \multicolumn{5}{|c|}{ Non-Working $(n=287)$} & \multicolumn{5}{|c|}{ Total Sample $(n=770)$} \\
\hline & $M$ & SD & Skew & Kurtosis & $\mathrm{se}^{a}$ & $M$ & SD & Skew & Kurtosis & $\mathrm{se}^{a}$ & $\bar{M}$ & SD & Skew & Kurtosis & $\mathrm{se}^{a}$ \\
\hline D1 & 2.52 & 0.92 & 0.40 & -0.52 & 0.04 & 2.77 & 0.96 & 0.19 & -0.82 & 0.06 & 2.61 & 0.94 & 0.32 & -0.66 & -0.03 \\
\hline D2 & 1.83 & 0.91 & 1.15 & 0.41 & 0.04 & 3.33 & 1.15 & 0.19 & -0.82 & 0.07 & 2.02 & 1.01 & 0.90 & -0.24 & 0.04 \\
\hline D3 & 1.74 & 0.79 & 1.27 & 1.27 & 0.04 & 2.03 & 0.96 & 0.96 & 0.26 & 0.06 & 1.85 & 0.86 & 1.18 & 0.93 & 0.03 \\
\hline D4 & 2.41 & 1.00 & 0.41 & -0.74 & 0.05 & 2.65 & 1.04 & 0.26 & -0.91 & 0.06 & 2.50 & 1.02 & 0.36 & -0.80 & 0.04 \\
\hline D5 & 2.48 & 1.13 & 0.43 & -0.82 & 0.05 & 2.88 & 1.26 & 0.11 & -1.13 & 0.07 & 2.76 & 1.01 & 0.19 & -0.87 & 0.05 \\
\hline D6 & 2.69 & 0.86 & 0.20 & -0.52 & 0.04 & 3.01 & 0.90 & -0.11 & -0.68 & 0.05 & 2.81 & 0.89 & 0.09 & -0.64 & 1.17 \\
\hline Total & 2.08 & 0.62 & 0.54 & -0.08 & 0.03 & 2.67 & 0.77 & 0.24 & -0.44 & 0.05 & 2.42 & 0.71 & 0.45 & -0.19 & 0.03 \\
\hline
\end{tabular}

${ }^{\mathrm{a} S t a n d a r d ~ e r r o r ~ o f ~ m e a n ~}$

Table 3 Confirmatory factor analysis (CFA) fit indices nonworking sample $(n=287)$

\begin{tabular}{lllllllll}
\hline Model & $X^{2}$ & p-value & $d f$ & $\frac{X^{2}}{d f}$ & CFI & TLI & RMSEA & SRMR \\
\hline 1 Factor & 3705.270 & $<0.001$ & 464 & 7.986 & 0.931 & 0.926 & 0.156 & 0.127 \\
2nd order 6F & 1094.409 & $<0.001$ & 458 & 2.389 & 0.986 & 0.985 & 0.070 & 0.077 \\
\hline
\end{tabular}


Table 4 Confirmatory factor analysis (CFA) fit indices working sample $(n=482)$
Table 5 Confirmatory factor analysis (CFA) fit indices imputed sample $(n=770)$

\begin{tabular}{lllllllll}
\hline Model & $X^{2}$ & p-value & $d f$ & $\frac{X^{2}}{d f}$ & CFI & TLI & RMSEA & SRMR \\
\hline 1 Factor & 9111.867 & $<0.001$ & 594 & 15.339 & 0.917 & 0.912 & 0.173 & 0.144 \\
2nd order 6F & 3708.296 & $<0.001$ & 588 & 6.307 & 0.970 & 0.968 & 0.105 & 0.100 \\
2nd order 7F & 1780.579 & $<0.001$ & 587 & 3.033 & 0.988 & 0.988 & 0.065 & 0.069 \\
\hline
\end{tabular}

\begin{tabular}{lrrllllll}
\hline Model & \multicolumn{1}{c}{$X^{2}$} & p-value & $d f$ & $\frac{X^{2}}{d f}$ & CFI & TLI & RMSEA & SRMR \\
\hline 1 Factor & $16,658.644$ & $<0.001$ & 594 & 28.04 & 0.904 & 0.898 & 0.188 & 0.161 \\
2nd order 6F & 6472.337 & $<0.001$ & 588 & 11.01 & 0.965 & 0.962 & 0.114 & 0.111 \\
2nd order 7F & 2574.417 & $<0.001$ & 587 & 4.386 & 0.988 & 0.987 & 0.066 & 0.065 \\
\hline
\end{tabular}

factors. For the working group, the second-order model with a general disability factor and seven factors on a lower level seems more appropriate (Table 4). Of note, the correlated traits model with seven factors had an even marginally better fit (see Online Supplement A). This model lends support to the aforementioned notion that subscale D5 contains two sub clusters with different content. However, a comparison of the item loadings in D5 between the working and non-working groups, showed no important differences. Therefore, it seems safe to assume that the D5 items measure the same underlying concept in both the working and non-working groups (standardized coefficients for all CFA models are provided in online supplement A).

Imputation is a suitable method for dealing with missing data that is convenient to use and easy to interpret [37]. To determine the effect of imputation of the missing values in the non-working group, we also evaluated all models by assigning the mean of 3 derived from the working group to the missing items D5.5-D5.8 in the non-working group, as proposed by the WHODAS 2.0 manual [5]. When imputing the missing D5 items in the non-working group by the mean of 3 , the second-order model with seven factors performed well (Table 5). The second-order model with six factors showed mixed results. It did not meet the pre-set threshold values for the RMSEA (0.114) and SRMR (0.111); but the CFI (0.965) and TLI (0.962) values corresponded to a good fit, though marginally worse compared to the second-order model with seven factors. Here it might also be of interest to point out that a correlated traits model with seven factors could compete with the second-order model with seven factors (see online supplement A). The reliability levels of the factors, as measured by coefficient $\omega$ (Table 6), were adequate $(\omega>0.80)$, except for the self-care factor within the working group $(\omega=0.76)$.

\section{Norms}

Percentile ranks and T-scores $(M=50, S D=10)$ for the mean scores were calculated (i.e., for all items and the 6
Table 6 Omega reliability values CFA

\begin{tabular}{|c|c|c|c|}
\hline & \multicolumn{3}{|l|}{ Omega $\omega$} \\
\hline & Working & Non-Working & Imputed $^{\mathrm{b}}$ \\
\hline 1 Factor & 0.95 & 0.95 & 0.95 \\
\hline \multicolumn{4}{|l|}{6 Factor } \\
\hline Cognition & 0.85 & 0.85 & 0.85 \\
\hline Mobility & 0.86 & 0.87 & 0.87 \\
\hline Self-care & 0.76 & 0.84 & 0.80 \\
\hline Getting along & 0.82 & 0.81 & 0.82 \\
\hline Life activities & 0.96 & 0.94 & 0.94 \\
\hline Participation & 0.84 & 0.85 & 0.85 \\
\hline 7 Factor & & N/A & \\
\hline Cognition & 0.85 & & 0.85 \\
\hline Mobility & 0.86 & & 0.87 \\
\hline Self-care & 0.76 & & 0.80 \\
\hline Getting along & 0.82 & & 0.82 \\
\hline Household & 0.93 & & 0.94 \\
\hline Work & 0.95 & & 0.93 \\
\hline Participation & 0.84 & & 0.85 \\
\hline 2 nd order $6 \mathrm{~F}$ & $0.85\left(\omega \mathrm{L} 1^{\mathrm{a}}\right)$ & $0.86\left(\omega \mathrm{L} 1^{1}\right)$ & $0.85\left(\omega \mathrm{L} 1^{\mathrm{a}}\right)$ \\
\hline Cognition & 0.85 & 0.85 & 0.85 \\
\hline Mobility & 0.86 & 0.87 & 0.87 \\
\hline Self-care & 0.76 & 0.84 & 0.80 \\
\hline Getting along & 0.82 & 0.81 & 0.82 \\
\hline Life activities & 0.96 & 0.94 & 0.95 \\
\hline Participation & 0.84 & 0.85 & 0.85 \\
\hline 2 nd order $7 F$ & $0.88\left(\omega \mathrm{L} 1^{\mathrm{a}}\right)$ & N/A & $0.87\left(\omega \mathrm{L} 1^{\mathrm{a}}\right)$ \\
\hline Cognition & 0.85 & & 0.85 \\
\hline Mobility & 0.86 & & 0.87 \\
\hline Self-care & 0.76 & & 0.80 \\
\hline Getting along & 0.82 & & 0.82 \\
\hline Household & 0.93 & & 0.94 \\
\hline Work & 0.95 & & 0.93 \\
\hline Participation & 0.84 & & 0.85 \\
\hline
\end{tabular}

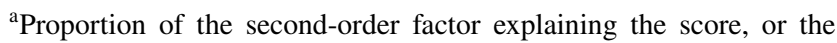
coefficient omega at Level 1

${ }^{\mathrm{b}}$ Imputation by a mean of 3 in the non-working group for items D5.5D5.8 
Table 7 Mean scores and corresponding percentile ranks WHODAS 2.0

\begin{tabular}{|c|c|c|c|c|c|c|c|}
\hline $\begin{array}{l}\text { Percentile } \\
\text { Label Domain }\end{array}$ & $\begin{array}{l}0 \% \\
\text { None }\end{array}$ & $\begin{array}{l}5 \% \\
\text { Mild }\end{array}$ & $\begin{array}{l}20 \% \\
\text { Mild/Moderate }\end{array}$ & $\begin{array}{l}40 \% \\
\text { Moderate }\end{array}$ & $\begin{array}{l}60 \% \\
\text { Moderate/ } \\
\text { Severe }\end{array}$ & $\begin{array}{l}80 \% \\
\text { Severe }\end{array}$ & $\begin{array}{l}95 \% \\
\text { Extreme }\end{array}$ \\
\hline \multicolumn{8}{|l|}{ Mean total score } \\
\hline Working & 0.89 & 1.14 & 1.53 & 1.86 & 2.14 & 2.58 & 3.19 \\
\hline Nonworking & 1.00 & 1.42 & 2.00 & 2.41 & 2.86 & 3.31 & 4.00 \\
\hline Total $(n=482)$ & 1.00 & 1.39 & 1.75 & 2.21 & 2.53 & 3.00 & 3.69 \\
\hline \multicolumn{8}{|l|}{ D1_Cognition } \\
\hline Working & 1.00 & 1.17 & 1.67 & 2.17 & 2.67 & 3.33 & 4.17 \\
\hline Nonworking & 1.00 & 1.33 & 1.83 & 2.50 & 3.00 & 3.67 & 4.45 \\
\hline Total $(n=770)$ & 1.00 & 1.67 & 1.67 & 2.33 & 2.83 & 3.50 & 4.67 \\
\hline \multicolumn{8}{|l|}{ D2_Mobility } \\
\hline Working & 1.00 & 1.00 & 1.00 & 1.20 & 1.80 & 2.60 & 3.80 \\
\hline Nonworking & 1.20 & 1.60 & 2.20 & 3.00 & 3.60 & 4.40 & 5.34 \\
\hline Total $(n=770)$ & 1.00 & 1.00 & 1.00 & 1.40 & 2.00 & 3.00 & 4.11 \\
\hline \multicolumn{8}{|l|}{ D3_Self-care } \\
\hline Working & 1.00 & 1.00 & 1.00 & 1.25 & 1.75 & 2.25 & 3.25 \\
\hline Nonworking & 1.00 & 1.00 & 1.25 & 1.50 & 2.00 & 3.00 & 4.00 \\
\hline Total $(n=770)$ & 1.00 & 1.00 & 1.00 & 1.50 & 1.75 & 2.50 & 3.75 \\
\hline \multicolumn{8}{|l|}{ D4_Getting along } \\
\hline Working & 1.00 & 1.00 & 1.40 & 2.00 & 2.60 & 3.40 & 4.64 \\
\hline Nonworking & 1.00 & 1.00 & 1.80 & 2.20 & 2.80 & 3.76 & 4.40 \\
\hline Total $(n=770)$ & 1.00 & 1.00 & 1.56 & 2.00 & 2.68 & 3.40 & 4.20 \\
\hline \multicolumn{8}{|l|}{ D5_Life activities } \\
\hline Working & 1.00 & 1.00 & 1.25 & 2.00 & 2.75 & 3.50 & 4.50 \\
\hline Nonworking & 1.00 & 1.00 & 1.75 & 2.50 & 3.00 & 4.00 & 5.00 \\
\hline Total $(n=482)$ & 1.00 & 1.00 & 1.56 & 2.00 & 2.68 & 3.40 & 4.80 \\
\hline \multicolumn{8}{|l|}{ D6_Participation } \\
\hline Working & 1.00 & 1.38 & 1.88 & 2.50 & 2.88 & 3.50 & 4.13 \\
\hline Nonworking & 1.00 & 1.54 & 2.13 & 2.75 & 3.38 & 3.88 & 4.46 \\
\hline Total $(n=770)$ & 1.00 & 1.38 & 2.00 & 2.50 & 3.00 & 3.63 & 4.25 \\
\hline
\end{tabular}

subscales) as shown in Tables 7 and 8. To illustrate, for the working group a mean score between 1.44 and 2.72 equals normalized T-scores between 40 and 60, which are considered moderate or average. Working patients with T-scores above this range (i.e., $1 S D>$ mean) might signal severe disability; patients with a T-score above 70 (i.e., $2 S D>$ mean) are likely to show extreme disability.

\section{Discussion}

This study describes the factor structure of the WHODAS 2.0 self-report version in a Dutch psychiatric outpatient sample. Particular attention has been given to the differences between the samples of the non-working group and the working group, as non-working was hypothesized to be associated with higher scores on the WHODAS 2.0 i.e., higher levels of disability. Characteristics of the psychiatric population were described, and percentile ranks with
T-scores were calculated to aid clinical decision making. The percentiles and T-scores reported in our study can be used to describe the relative impairment in relation to other patients with common mental disorders in ambulatory care.

We used CFA for evaluating dimensionality. The unidimensional model did not meet the recommended criteria for a good fit. Our results indicate that the multidimensional factor solution previously found for the interview version [9], can also be extended to the WHODAS 2.0 self-report version. The reliability levels of the tested factor models, as measured by coefficient $\omega$, all exceeded 0.80 , which we consider to be sufficient.

For the non-working group, the second-order model with a general disability factor and six factors on a lower level, provided an adequate fit. Hence, for this group, the original factor composition of the WHODAS 2.0 interview version seems also adequate for the WHODAS 2.0 selfreport version as well. Although a correlated six-factor model performed even slightly better in terms of fit (see 
Table 8 Conversion table of raw mean scores to corresponding T-scores WHODAS 2.0

\begin{tabular}{|c|c|c|c|c|c|}
\hline & \multicolumn{5}{|l|}{ T-scores } \\
\hline & 30 None & 40 Mild & 50 Moderate & 60 Severe & 70 Extreme \\
\hline \multicolumn{6}{|l|}{ Mean total score } \\
\hline Working & 1.03 & 1.44 & 2.00 & 2.72 & 3.56 \\
\hline Nonworking & 1.31 & 1.88 & 2.63 & 3.50 & 4.28 \\
\hline Total $(n=482)$ & 1.22 & 1.67 & 2.36 & 3.17 & 4.06 \\
\hline \multicolumn{6}{|l|}{ D1_Cognition } \\
\hline Working & 1.17 & 1.67 & 2.50 & 3.50 & 4.50 \\
\hline Nonworking & 1.17 & 1.83 & 2.67 & 3.83 & 4.67 \\
\hline Total $(n=770)$ & 1.17 & 1.67 & 2.50 & 3.67 & 4.67 \\
\hline \multicolumn{6}{|l|}{ D2_Mobility } \\
\hline Working & N/A & 1.00 & 1.60 & 2.80 & 4.20 \\
\hline Nonworking & 1.40 & 2.00 & 3.20 & 4.60 & 5.60 \\
\hline Total $(n=770)$ & N/A & 1.00 & 1.80 & 3.20 & 4.40 \\
\hline \multicolumn{6}{|l|}{ D3_Self-care } \\
\hline Working & N/A & 1.00 & 1.50 & 2.50 & 3.75 \\
\hline Nonworking & N/A & 1.25 & 1.75 & 3.00 & 4.25 \\
\hline Total $(n=770)$ & N/A & 1.00 & 1.50 & 2.75 & 4.00 \\
\hline \multicolumn{6}{|l|}{ D4_Getting along } \\
\hline Working & N/A & 1.40 & 2.40 & 3.60 & 4.40 \\
\hline Nonworking & N/A & 1.60 & 2.60 & 3.80 & 4.60 \\
\hline Total $(n=770)$ & N/A & 1.40 & 2.40 & 3.60 & 4.60 \\
\hline \multicolumn{6}{|l|}{ D5_Life activities } \\
\hline Working & N/A & 1.25 & 2.25 & 4.00 & 4.75 \\
\hline Nonworking & N/A & 1.50 & 2.75 & 4.25 & N/A \\
\hline Total $(n=482)$ & 1.00 & 1.63 & 2.75 & 3.88 & 4.75 \\
\hline \multicolumn{6}{|l|}{ D6_Participation } \\
\hline Working & 1.13 & 1.75 & 2.63 & 3.63 & 4.50 \\
\hline Nonworking & 1.13 & 2.00 & 3.00 & 4.00 & 4.63 \\
\hline Total $(n=770)$ & 1.13 & 1.88 & 2.75 & 3.75 & 4.63 \\
\hline
\end{tabular}

Online Supplement A), we suggest using this second-order model based on previous findings on the factor structure of the interview version and these small differences.

However, for the working group, a second-order model with a general disability factor and seven factors on a lower level seems more appropriate. A correlated traits model with seven factors, has an even (slightly) better fit (see Online Supplement A); but there seems no compelling reason to deviate from the second-order structure that is in line with previous findings.

Conceptually, this can be explained, as the item content of subscale D5 (life activities) contains two types of items: household items (D5.1-D5.4) and work/school activities items (D5.5-5.8). Separate subscales for these subdomains could represent the item content more clearly for clinicians and patients in daily practice. For the further development of the WHODAS 2.0, it might therefore be advisable to divide subscale D5 (life activities) into two separate subscales, separating the household items from the work/school activities items [12], and to consider imputing the missing D5 items in the non-working group using the mean value of 3 . However, it should be noticed that the differences in terms of fit across the various factor models are modest.

It is also worth considering if not working in itself is a sign of increased disability [12]. This seems plausible, given the differences in the mean scores between the nonworking group and working group. This implies that the non-working group is relatively more impaired, or has a relatively higher level of functional disability, compared to the working group.

While the WHODAS 2.0 is considered a generic assessment instrument that can be used in both clinical and general population settings, the response patterns found in subscales D2 (Mobility) and D3 (Self-care) could be an indication that these domains are of less interest, when measuring the level of disability of psychiatric patients. This would not be an unexpected finding, since it has been found that psychiatric patients with common mental disorders are not likely to reach out to mental healthcare services, primarily because of mobility or self-care issues [38]. Nevertheless, our data 
show that a minority of the patients endorses the higher response categories for the aforementioned items. Therefore, these items seem valuable for assessing the more severe levels of disability. This is important, because for a generic instrument, items covering the full range of the underlying trait levels are necessary.

\section{Limitations}

Although, our total sample size was substantial, the sample of the non-working group was relatively small, which could affect the outcome of the CFA. In addition, the majority of participants (70\%) had a primary diagnosis of a depressive disorder or an anxiety disorder, and for $16 \%$ the primary diagnosis was unknown. Therefore, generalizability to other psychiatric groups-especially, those with severe functional impairment—might be limited. That being said, we deem our cross-sectional study is a valuable starting point for implementing the self-report method for measuring the level of disability in psychiatric patients.

Another limitation of this study is that, despite the fact that we have found some evidence that a seven-factor model could be an improvement, external validation is necessary to substantiate this assumption. For instance, is a seven-factor model better in differentiating patients with a positive versus negative treatment outcome? We further suggest that more research should be done on the responsiveness of the WHODAS 2.0. Finally, it is important to analyze data from the Dutch general population for establishing an agreed-upon cut-point for identifying healthy subjects.

\section{Conclusion}

Our results lend support for a factorial structure of the WHODAS 2.0 36-item self-report version that is comparable to the interview version. Based on our results, we conclude that a multidimensional model is preferred, and that the subscales of the WHODAS 2.0 36-item self-report form have added value when measuring the level of functioning. While we conjecture that a seven-factor solution might give a better reflection of item content and item variance, further research is needed to assess the clinical relevance of such a model. At this point, we recommend using the second-order structure with six factors that matches past findings of the interview form.

In sum, we consider the WHODAS 2.036 -item selfreport form a promising measure for assessing the level of functioning in Dutch psychiatric patients, in compliance with the international recommendations of the WHO,
ICHOM, DSM-5 and the guidelines of the Dutch Healthcare Institute [5-7, 14].

Supplementary Information The online version contains supplementary material available at https://doi.org/10.1007/s11136-021-02880-8.

Acknowledgements The researchers would like to offer their special thanks for the invaluable assistance and support given by: (i) E. de Groot, senior staff advisor of the Research and Innovation team from the Dimence Group. (ii) A. Kaal, senior business intelligence developer of the Business Intelligence Team from the Dimence Group. (iii) M.J. Paap, English language editor.

Funding The first author received financial support from the Dimence Group for the research, authorship, and publication of this article.

Data availability The data that support the findings of this study are available from the Dimence Group. Note that restrictions apply to the availability of these data, which were used under license for the current study, and for that reason are not publicly available. However, data are available from the authors upon reasonable request and with permission of the Dimence Group.

Code availability The $\mathrm{R}$ codes used for analysis are available from the corresponding author upon reasonable request.

\section{Declarations}

Conflict of interest The author(s) declared no potential conflicts of interest with respect to the research, authorship, and/or publication of this article.

Ethical approval This study is part of a larger study concerning the development of Computerized Adaptive Tests for measuring the level of functioning in psychiatric patients. The Medical Ethics Review Committee (MERC) of VU University Medical Center (VUmc) confirmed that the Medical Research Involving Humans Subjects Act (WMO) does not apply to this study, and an official approval by the MERC is not required. The MERC of VUmc is registered with the US Office for Human Research Protections (OHRP) as IRB00002991. The FWA number assigned to the VUmc is FWA00017598. All patients received an information brochure upon their referral and registration for treatment, informing them that their personal (coded) data could be used for research, and that, if they did not consent to this, an opt-out procedure was available by filling-out the "objection to use anonymous data" form. This optional opt-out choice would be registered in their personal electronic health record. Data from patients with an opt-out registration are never released or used for data analysis. The privacy and information security officer of the DG also confirmed that we were allowed to use the data available for our study, because all data was encoded, i.e., could not be traced back to a person. The researchers had no direct access to the database itself, and only had the coded, raw data, at their disposal.

Open Access This article is licensed under a Creative Commons Attribution 4.0 International License, which permits use, sharing, adaptation, distribution and reproduction in any medium or format, as long as you give appropriate credit to the original author(s) and the source, provide a link to the Creative Commons licence, and indicate if changes were made. The images or other third party material in this article are included in the article's Creative Commons licence, unless indicated otherwise in a credit line to the material. If material is not included in the article's Creative Commons licence and your intended use is not 
permitted by statutory regulation or exceeds the permitted use, you will need to obtain permission directly from the copyright holder. To view a copy of this licence, visit http://creativecommons.org/licenses/by/4.0/.

\section{References}

1. Douglas, H., Georgiou, A., \& Westbrook, J. (2017). Social participation as an indicator of successful aging: An overview of concepts and their associations with health. Australian Health Review, 41, 455-462. https://doi.org/10.1071/AH16038

2. Carver, L., Beamish, R., Phillips, S., \& Villeneuve, M. (2018). A scoping review: Social participation as a cornerstone of successful aging in place among rural older adults. Geriatrics, 3, 75. https:// doi.org/10.3390/geriatrics3040075

3. Cuijpers, P. (2019). Targets and outcomes of psychotherapies for mental disorders: an overview. World Psychiatry, 18, 276-285.

4. World Health Organization. (2002). Towards a common language for functioning, disability and health: ICF-The international classification of functioning, disability and health. World Health Organization.

5. Üstün, T. B., Kosstanjsek, N., Chatterji, S., \& Rehm, J. (Eds.). (2010). Measuring health and disability: Manual for WHO disability assessment schedule WHODAS 2.0. World Health Organization.

6. Obbarius, A., van Maasakkers, L., Baer, L., Clark, D. M., Crocker, A. G., de Beurs, E., Emmelkamp, P. M. G., et al. (2017). Standardization of health outcomes assessment for depression and anxiety: Recommendations from the ICHOM Depression and Anxiety Working Group. Quality of Life Research, 26, 3211-3225. https:// doi.org/10.1007/s11136-017-1659-5

7. American Psychiatric Association. (2013). Diagnostic and statistical manual of mental disorders (5th ed.). American Psychiatric Publishing.

8. Gold, L. H. (2014). DSM-5 and the assessment of functioning: The World Health Organization Disability Assessment Schedule 20 (WHODAS 20). The Journal of the American Academy of Psychiatry and the Law, 42, 173-181.

9. Üstün, B., Chatterji, S., Kostanjsek, N., Rehm, J., Kennedy, C., Epping-Jordan, J., Saxena, S., von Korff, M., \& Pull, C. (2010). Developing the World Health Organization disability assessment schedule 2.0. Bulletin of the World Health Organization, 88, 815823. https://doi.org/10.2471/BLT.09.067231

10. Federici, S., Bracalenti, M., Meloni, F., \& Luciano, J. V. (2017). World Health Organization disability assessment schedule 2.0: An international systematic review. Disability and Rehabilitation, 39, 2347-2380. https://doi.org/10.1080/09638288.2016.1223177

11. Cuijpers, P., Juan, L., Hofmann, S. G., \& Andersson, G. (2010). Self-reported versus clinician-rated symptoms of depression as outcome measures in psychotherapy research on depression: A meta-analysis. Clinical Psychology Review, 30, 768-778. https:// doi.org/10.1016/j.cpr.2010.06.001

12. Garin, O., Ayuso-Mateos, J., Almansa, J., Nieto, M., Chatterji, S., Vilagut, G., Alonso, J., et al. (2010). Validation of the "World Health Organization Disability Assessment Schedule, WHODAS-2" in patients with chronic diseases. Health and Quality of Life Outcomes, 8, 51. https://doi.org/10.1186/1477-7525-8-51

13. American Psychiatric Association. (2014). Handboek voor de classificatie van psychische stoornissen (1st ed.). Boom uitgevers.

14. Akwa GGZ. 2020. Vroege opsporing van psychische klachten en aandoeningen in de volwassen bevolking, 9.10.13 Screeningsinstrumenten naar functionele beperkingen. https://www.ggzstandaa rden.nl/generieke-modules/vroege-opsporing-van-psychischeklachten-en-aandoeningen-in-de-volwassen-bevolking/introductie
15. Konecky, B., Meyer, E. C., Marx, B. P., Kimbrel, N. A., \& Morissette, S. B. (2014). Using the WHODAS 2.0 to assess functional disability associated with DSM5 mental disorders. American Journal of Psychiatry, 171, 818-819. https://doi.org/10.1176/ appi.ajp.2014.14050587

16. Cella, D., Yount, S., Rothrock, N., Gershon, R., Cook, K., Reeve, B., Ader, D., Fries, J. F., Bruce, B., \& Rose, M. (2007). The patient-reported outcomes measurement information system (PROMIS). Medical Care, 45, S3-S11. https://doi.org/10.1097/ 01.mlr.0000258615.42478.55

17. Wahl, I., Löwe, B., Bjorner, J. B., Fischer, F., Langs, G., Voderholzer, U., Aita, S. A., Bergemann, N., Brähler, E., \& Rose, M. (2014). Standardization of depression measurement: A common metric was developed for 11 self-report depression measures. Journal of Clinical Epidemiology, 67, 73-86. https://doi.org/10. 1016/j.jclinepi.2013.04.019

18. Schalet, B. D., Cook, K. F., Choi, S. W., \& Cella, D. (2014). Establishing a common metric for self-reported anxiety: Linking the MASQ, PANAS, and GAD-7 to PROMIS Anxiety. Journal of Anxiety Disorders, 28, 88-96. https://doi.org/10.1016/j.janxd is.2013.11.006

19. RCore Team. (2019). $R$ : A language and environment for statistical computing. $\mathrm{R}$ Foundation for Statistical Computing.

20. Rosseel, Y. (2012). lavaan: An R package for structural equation modeling. Journal of Statistical Software, 48, 1-36.

21. Wickham, H., Averick, M., Bryan, J., Chang, W., McGowan, L. D., François, R., et al. (2019). Welcome to the tidyverse. Journal of Open Source Software, 4(43), 1686. https://doi.org/10.21105/ joss.01686.

22. Revelle, W. (2018). psych: Procedures for psychological, psychometric, and personality research. Northwestern University.

23. Jorgensen, T. D., Pornprasertmanit, S., Schoemann, A. M., \& Rosseel, Y. 2019. semTools: Useful tools for structural equation modeling. R package version $0.5-2$

24. Epskamp, S. 2019. semplot: Path diagrams and visual analysis of various SEM Packages' Output.

25. Willse, J.T. 2018. CTT: Classical test theory functions.

26. Torchiano, M. (2020). Effsize: Efficient effect size computation. Viena: R Foundation for Statistical Computing. https://doi.org/10. 5281/zenodo. 1480624

27. McNeish, D. (2017). Thanks coefficient alpha, we'll take it from here. Psychological Methods. https://doi.org/10.1037/met0000144

28. Antony, M. M., \& Barlow, D. H. (Eds.). (2010). Handbook of assessment and treatment planning for psychological disorders (2nd ed.). New York: The Guilford Press.

29. Black, R. A., Yang, Y., Beitra, D., \& McCaffrey, S. (2015). Comparing fit and reliability estimates of a psychological instrument using second-order CFA, bifactor, and essentially tau-equivalent (coefficient alpha) models via AMOS 22. Journal of Psychoeducational Assessment, 33, 451-472. https://doi.org/10.1177/07342 82914553551

30. Meijer, R., Niessen, S., \& Boevé, A. (2015). Rapporteren van Subtestscores in de Klinische Praktijk. De Psycholoog, 50, 34-42.

31. Nunnally, J., \& Bernstein, I. (1968). Psychometric theory. American Educational Research Journal. https://doi.org/10.2307/11619 62

32. Lance, C. E., Butts, M. M., \& Michels, L. C. (2006). What did they really say? Organizational Research Methods, 9, 202-220. https://doi.org/10.1177/1094428105284919

33. Brown, T. (2015). Confirmatory factor analysis for applied research. New York: Guilford Press.

34. Li, C. H. (2016). Confirmatory factor analysis with ordinal data: Comparing robust maximum likelihood and diagonally weighted least squares. Behavior Research Methods, 48, 936-949. https:// doi.org/10.3758/s13428-015-0619-7 
35. Reeve, B. B., Hays, R. D., Bjorner, J. B., Cook, K. F., Crane, P. K., Teresi, J. A., Thissen, D., et al. (2007). Psychometric evaluation and calibration of health-related quality of life item banks. Medical Care, 45, S22-S31. https://doi.org/10.1097/01.mlr.00002 50483.85507.04

36. Schreiber, J. B., Stage, F. K., King, J., Nora, A., \& Barlow, E. A. (2006). Reporting structural equation modeling and confirmatory factor analysis results: A review. Journal of Educational Research, 99, 323-338. https://doi.org/10.3200/JOER.99.6.323-338

37. Cohen, J. (1988). Statistical power analysis for the behavioral sciences (2nd ed.). New York: Routledge Academic.
38. Good, D. V., Jo, M., Good, B. J., \& Nassi, A. J. (1983). Patient requests in primary health care settings: Development and validation of a research instrument. Journal of Behavioral Medicine, 6, 151-168. https://doi.org/10.1007/BF00845378

Publisher's Note Springer Nature remains neutral with regard to jurisdictional claims in published maps and institutional affiliations. 